\title{
Lightning stroke distance estimation from single station observation and validation with WWLLN data
}

\author{
V. Ramachandran, J. N. Prakash, A. Deo, and S. Kumar \\ School of Engineering and Physics, University of the South Pacific, Suva, Fiji \\ Received: 3 December 2006 - Revised: 2 June 2007 - Accepted: 27 June 2007 - Published: 30 July 2007
}

\begin{abstract}
A simple technique to estimate the distance of the lightning strikes $d$ with a single VLF electromagnetic wave receiver at a single station is described. The technique is based on the recording of oscillatory waveforms of the electric fields of sferics. Even though the process of estimating $d$ using the waveform is a rather classical one, a novel and simple procedure for finding $d$ is proposed in this paper. The procedure adopted provides two independent estimates of the distance of the stroke. The accuracy of measurements has been improved by employing high speed (333 ns sampling rate) signal processing techniques. GPS time is used as the reference time, which enables us to compare the calculated distances of the lightning strikes, by both methods, with those calculated from the data obtained by the World-Wide Lightning Location Network (WWLLN), which uses a multistation technique. The estimated distances of the lightning strikes (77), whose times correlated, ranged from $\sim 3000$ $16250 \mathrm{~km}$. When $d<3500 \mathrm{~km}$, the average deviation in $d$ compared with those calculated with the multi-station lightning location system is $\sim 4.7 \%$, while for all the strokes it was $\sim 8.8 \%$. One of the lightnings which was recorded by WWLLN, whose field pattern was recorded and the spectrogram of the sferic was also recorded at the site, is analyzed in detail. The deviations in $d$ calculated from the field pattern and from the arrival time of the sferic were $3.2 \%$ and $1.5 \%$, respectively, compared to $d$ calculated from the WWLLN location. FFT analysis of the waveform showed that only a narrow band of frequencies is received at the site, which is confirmed by the intensity of the corresponding sferic in the spectrogram.
\end{abstract}

Keywords. Meteorology and atmospheric dynamics (Lightning) - Electromagnetics (Guided waves) - Radio science (Atmospheric propagation)

Correspondence to: V. Ramachandran (ramachandran@usp.ac.fj)

\section{Introduction}

A technique of locating the source of lightning by a single station would markedly improve the research of atmospherics. In the inverse technique of interpreting the unknown spectrum of the source (i.e. the parent lightning discharge) from the received spectra at a site, one important parameter required is the distance of the stroke from the receiver. Lineof-sight "ground waves" from the stroke provide information on source characteristics. Lightning locations are also useful in providing weather data over wide regions, in climate studies and for meteorological forecasting. It is well established that lightning produces a wide spectrum of electromagnetic radiation with peak spectral density in the VLF $(3-30 \mathrm{kHz})$ band centered $\sim 10 \mathrm{kHz}$. The lightning-generated VLF impulses (sferics) travel in the Earth-Ionosphere WaveGuide (EIWG) with very little attenuation $(2-3 \mathrm{~dB} / \mathrm{Mm}$ ) (Wood and Inan, 2002). This band of spectrum is studied in this paper.

The quest of lightning location can be solved by means of multi-station or single-station techniques. Multi-station techniques are the most accurate and several systems have been developed in the past decades. The different systems available for lightning remote sensing have complementary levels of detail, range, and application. To summarize a few: Lightning-Mapping Arrays (Rison et al., 1999; Thomas et al., 2000), UK Met Office VLF system (Lee, 1986a, b, 1989), the U.S. National Lightning Detection Network (Cummins et al., 1998), the Los Alamos Sferic Array (LASA) (Smith et al., 2002), the Europe ZEUS system (Chronis and Anagnostou, 2003), World-Wide Lightning Location Network (WWLLN) (Dowden et al., 2002; Lay et al., 2005; Rodger et al., 2005). Lightning Imaging Sensor (LIS) aboard the TRMM satellite provides data on global lightning activity but with less detail (Boccippio et al., 1999).

Single-site lightning location systems usually combine a direction finder with a technique to estimate the distance of the source. Analyzing the smooth-type sferics field patterns

Published by Copernicus Publications on behalf of the European Geosciences Union. 
received on an oscilloscope at a station, Hepburn (1960) estimated the distance of the lightning strikes. In this analysis, the smooth oscillatory waveform was assumed to be quasiperiodic. For a stroke distance of $d$ and lower ionosphere height $h$, the quasi-periods $\tau$ and their delay times $T$ were predicted to be related as

$T=d\left[\left(1-\tau^{2} c^{2} / 4 h^{2}\right)^{-1 / 2}-1\right] / c$.

A family of delay vs. quasi-period curves ( $T-\tau$ plots) were drawn for different values of $d$ with $h=85 \mathrm{~km}$. By curvefitting the experimental $T$ and $\tau$ plots with the theoretical plots, the distance of the stroke was estimated. Hepburn (1960) reported that the theoretical and experimental plots had a deviation of $\sim 17.5 \%$ when mean $d<3200 \mathrm{~km}$, with an increase in the deviation as the distance increased. A similar approach has been used by Rao (1968), but with $h$ as $80 \mathrm{~km}$, and reported $\pm 10 \%$ to $\pm 15 \%$ deviation in the two plots.

The separation $\tau$ between the onset of the VLF component and the first maximum of the "slow tail" is derived by Wait (1962, p 314) and is given by

$\tau=0.09\left[\frac{d}{2 h \sqrt{\omega_{r}}}+\delta^{\frac{1}{2}}\right]^{2}$,

where $\omega_{r}$ is the conductivity parameter of the ionosphere and $\delta$ is an approximately constant term corresponding to the pulse width at the source impulse. By measuring $\tau$, a real-time distance estimation of lightning strikes using sferics recordings at a single station has been developed (Sao and Jindoh, 1974).

Using the general expression for the phase of the $n$th mode derived by Wait (1962, p 290), Rafalsky et al. (1995) obtained the expression for the phase of the $n$th mode at a receiver at a distance $d$ as

$F_{n}=k d\left(S_{n}-1\right)$,

where $S_{n}=\left[1-\left(\frac{n \pi}{k h}\right)^{2}\right]^{\frac{1}{2}}$ and $k=2 \pi f / c$. Assuming $h$ as $86.9 \mathrm{~km}$ with the frequency interval restricted to $1.8-3.2 \mathrm{kHz}$ (mode 1), the phase vs. frequency spectrum for the first order mode was theoretically computed for different $d$ values and compared with the experimental phase plot of the $H_{z}$ field. The discrepancy in the estimation of $d$ was reported to be between 5 to $7 \%$ when $d$ was in the range of 3000 to $3500 \mathrm{~km}$.

When the lightning flashes are strong enough, they produce experimentally detectable Shumann resonance patterns. It has been reported (Boccippio et al., 1998) that by measuring the ELF transients and computing the range-dependent complex wave impedance, lightning locations were detected; however, the error was $0.5-2.0 \mathrm{Mm}$. Price et al. (2002) reported an ELF/VLF method for globally locating spriteproducing lightning. The VLF magnetic components were used to find the azimuth while the wave impedance of the
ELF components gave the distance of the stroke. For positive cloud-to-ground lightning they have reported a mean error of $1.6 \%$. In the single station lightning location system reported by Itano et al. (2006), sequential pulses appearing on the waveform of each VLF sferic were used to estimate the distance to the corresponding lightning return stroke. The location error was reported as $\sim 10 \%$.

In this paper, we describe a novel, simple and cost effective system to estimate the distance of the lightning strikes with a single VLF electromagnetic wave receiver at a single station. Our technique is based on the observation of oscillatory waveforms of the sferics fields. A simple procedure for finding $d$ using the period and the delay extracted from the quasiperiodic waveform of the electric field received at the station is described in this paper. By employing sophisticated signal processing techniques, we also try to improve the accuracy for measurement of the sferics' waveform arrival times. The waveforms were recorded with respect to GPS times, which are then correlated with stroke times recorded by WWLLN, which is a multi-station location system. A recent comparative study of LASA-WWLLN by Jacobson et al. (2006) have shown a very good correlation (15-20 km) of lightning location. The distances calculated using the times recorded from the waveforms are then correlated with the distances calculated from WWLLN locations and stroke times. The distances so calculated are then used to correlate with the sferics in the spectrogram recorded at the site.

\section{Theory}

The current in a typical lightning return stroke reaches its peak value in $\sim 2 \mu \mathrm{s}$ and decays to a half peak in $\sim 40 \mu \mathrm{s}$ (Uman, 1987, p 77). This results in a short pulse of electromagnetic radiation $\sim 100 \mu$ s covering a very wide band of frequencies. Lee (1989) points out that effectively all the VLF power from the first return stroke comes from the lowest $2 \mathrm{~km}$, which is a small fraction of a wavelength in the VLF band $(10-100 \mathrm{~km})$, so the source of the VLF radiation is a short current element. Thus, we can assume that the phase of all the VLF Fourier components of the current is the same so that the initial phase is the same for all the VLF Fourier components of the radiated electric field.

Consider TM mode propagation of the sferics in a simple form (parallel plate) of EIWG. Assuming the cutoff frequency of the EIWG as $f_{c}$, the phase constant for the Fourier component of frequency $f$ propagating in the waveguide is (Rao, 2004, p 552)

$k=\frac{\omega}{c}\left[1-\left(\frac{f_{c}}{f}\right)^{2}\right]^{\frac{1}{2}}$,

and the phase velocity is

$v_{p}=\frac{\omega}{k}$. 
Dowden et al. (2002) assumed the constant initial phase angle of the individual Fourier components as zero, and expressed the waveform at a distance $d$ from the source for the different frequencies as $A(\omega) \cos \left[\omega\left(t-\frac{d}{v_{p}}\right)\right]$, where $A(\omega)$ is a weighting function given by $\cos ^{2}\left(\pi \frac{\omega-\omega_{a}}{2 \omega_{r}}\right)$, where $\omega_{a}$ is the frequency of peak spectral density $(10 \mathrm{kHz})$, and $\omega_{r}$ is chosen to correspond to the bandwidth. Assuming $\omega_{r}$ as $14 \mathrm{kHz}$ so that the half power frequencies are 5 and $19 \mathrm{kHz}$, which is typical of sferic spectra, they then synthesized the sferic waveform at different distances $d$ by summing 100 waveforms. The plots showed that the wave packet expands with distance $d$.

On a conventional oscilloscope, triggered by the incoming pulse, the trace of the sferic field will appear as the trace in Fig. 1. (This trace was obtained by passing one of the waveform data recorded on the picoscope through a low pass filter available in the MATLAB program.) We can interpret the trace as follows: the high frequency Fourier components of the sferic field $\left(f \gg f_{c}\right)$, all traveling with a speed $c$, arrive at the same time $t_{0}$ (with respect to the lightning stroke time), at a receiver a distance $d$ from the source. The lower frequency components of the sferics field $\left(f>f_{c}\right.$ but close to $f_{c}$ ), will, however, undergo dispersion. If we consider a narrow band of signals in this region, they superimpose, giving rise to a quasi-periodic wave, and travel with the group velocity $v_{g}$. For frequency components $f$ close to the cutoff frequency, the group velocity $v_{g}=d \omega / d k$. Using Eq. (4)

$v_{g}=c\left[1-\left(\frac{f_{c}}{f}\right)^{2}\right]^{\frac{1}{2}}$.

The group velocities progressively decrease as $f$ approach $f_{c}$. The synthesized waveform reported by Dowden et al. (2002) for $d>1000 \mathrm{~km}$ was very similar to the trace from A-K of Fig. 1.

In the treatment presented in this paper, the oscillatory portion of the sferic field pattern is considered to be composed of quasi-periodic waves of different frequencies. In Fig. 1, the portion of the waveform starting from $\mathrm{A}$ to $\mathrm{K}$ is oscillatory. We assume that the frequency of the quasi-periodic wave $\mathrm{A}-\mathrm{C}$ is

$f=\frac{1}{T_{C}-T_{A}}$

and is received at a time $\left(t_{o}+T_{B}\right)$ with respect to the stroke time. Similarly, the quasi-periodic wave B-D of frequency $f=1 /\left(T_{D}-T_{B}\right)$ is received at a time $\left(t_{o}+T_{C}\right)$, etc. In general, the time $T_{B}, T_{C}$ with respect to the start of the trace is represented as $T$ in what follows. Note that $f$ is greater than the cutoff frequency $f_{c}$ of the EIWG. For a group of waves around frequency $f\left(>f_{c}\right)$, the time of arrival at the site is related as

$t_{0}+T=\frac{d}{v_{g}}$,

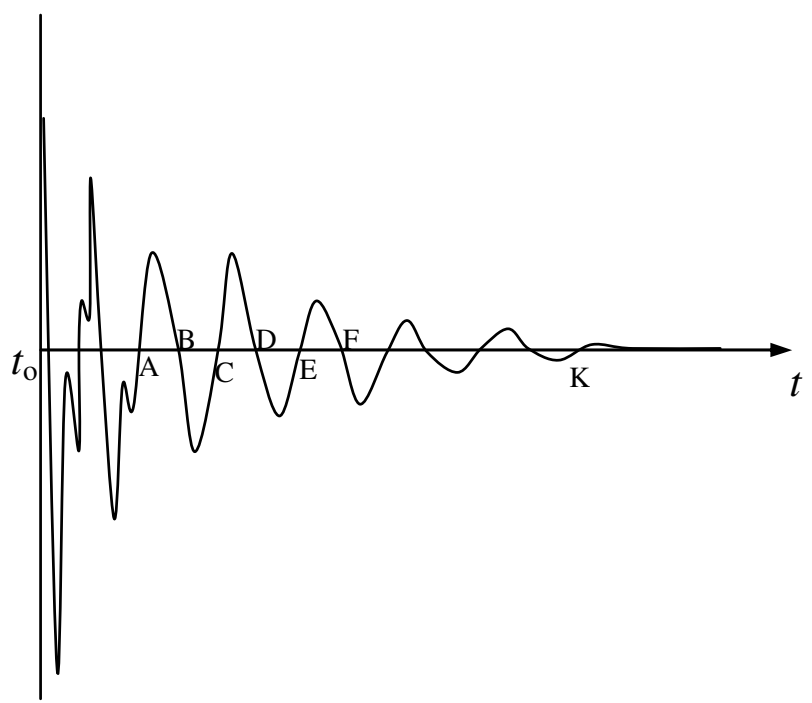

Fig. 1. Typical waveform of sferic field pattern.

where $t_{0}=\frac{d}{c}$. Substituting for $t_{o}$ and $v_{g}$,

$T=\frac{d}{c} \frac{1}{\left[1-\left(\frac{f_{c}}{f}\right)^{2}\right]^{\frac{1}{2}}}-\frac{d}{c}$.

Equation (9) is identical to Eq. (1) proposed by Hepburn (1960), where $c /(2 h)$ is the cutoff frequency $f_{c}$ of the EIWG and $\tau$ is the period $(=1 / f)$ of the quasi-periodic wave. It is interesting to note that when the phase difference is computed after a time $T$, it is identical to Eq. (3) proposed by Rafalsky et al. (1995).

From Eq. (9) it is seen that in a graph of $T$ vs. $\left[1-\left(\frac{f_{c}}{f}\right)^{2}\right]^{-\frac{1}{2}}$, the slope is $\frac{d}{c}$ and the intercept is $-\frac{d}{c}$, thus providing two independent methods of calculating the source distance.

\section{Experimental setup}

University of the South Pacific, Fiji (Lat. $18^{\circ} 08^{\prime} \mathrm{S}$, Long. $178^{\circ} 27^{\prime} \mathrm{E}$ ) is one of 28 Universities/Institutions which participate in the global lightning detection program under WWLLN. This network uses the Time Of Group Arrival (TOGA) method for lightning location. Detailed theory of the TOGA principle and a description of the measurement method can be found in Dowden and Rodger (2001), Dowden et al. (2002).

The VLF receiving system consists of a whip antenna and a GPS antenna. The VLF antenna is approximately $5 \mathrm{~m}$ of a 1-mm stranded wire folded inside a PVC pipe about $2 \mathrm{~m}$ long. The PVC pipe was fixed to a metal pipe of $\sim 2 \mathrm{~m}$ long with an overlap of $\sim 30 \mathrm{~cm}$ and the whole arrangement is 

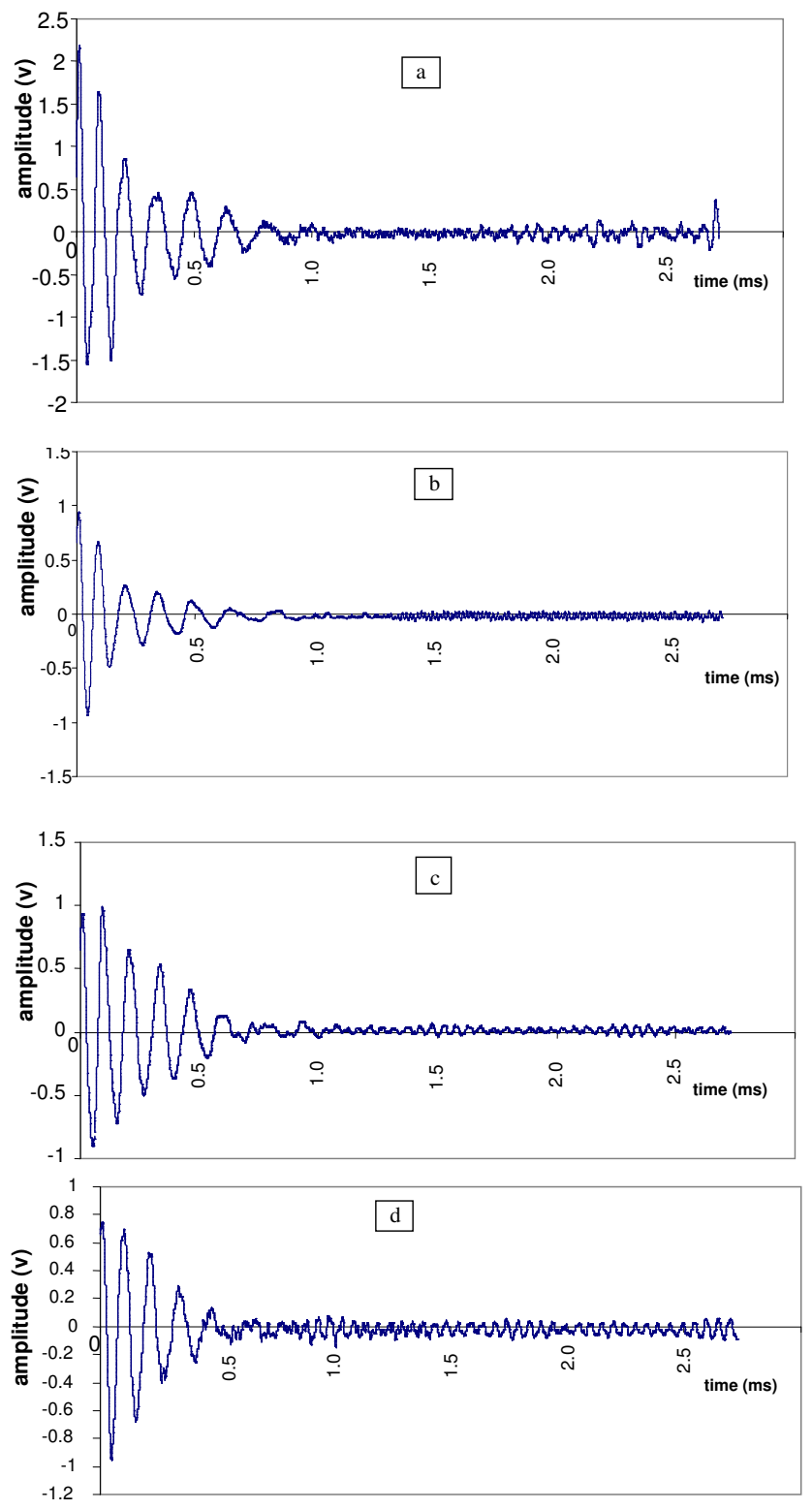

Fig. 2. Electric fields of sferics registered in September, 2006. (a) 13:01:06 LT - 01:01:06 UT (28 September), (b) 19:00:28 LT - 07:00:28 UT (8 September), (c) 23:00:06 LT - 11:00:06 UT (3 September), (d) 03:04:04 LT - 15:04:04 UT (23 September).

mounted on top of the roof of a two-storey building. The GPS antenna is also fitted on the roof about $10 \mathrm{~m}$ from the VLF antenna. The VLF output of the antenna is first amplified by a VLF preamplifier which has two parallel outputs. The peak output voltage of the preamplifier is $10 \mathrm{~V}$. The amplifier has a distributed RC filter which has attenuation in $\mathrm{dB}$ proportional to the square root of the frequency. (i.e. $\sim 6 \mathrm{~dB}$ at $40 \mathrm{kHz}$, and $\sim 48 \mathrm{~dB}$ at $2.5 \mathrm{MHz}$ ). The GPS antenna output is connected to a splitter which has two outputs. One of the outputs of the preamplifier and one from the splitter are fed into a "service unit", which contains the VLF sensor and the GPS "engine", whose output is fed to the sound card of a PC(1) used for TOGA measurement. A detailed description of the experimental setup used at the site is given in Ramachandran et al. (2005). The processing centre of WWLLN at University of Seattle, Washington provides the participating Institutions with monthly data of lightning locations and the stroke times (accurate to $\mu \mathrm{s}$ ), on a CD. Using the WWLLN program which is installed on the $\mathrm{PC}(1)$ at our station we can simultaneously record the spectrogram of the sferics received, and these can be later extracted using MATLAB codes.

The other output of the preamplifier and the GPS is used to record the waveforms of the sferics. This second output of the preamplifier is fed to a high speed picoscope (Pico ADC 212/3), which has a sampling rate of $3 \mathrm{MS} / \mathrm{s}$, with an accuracy of $1 \%$. The picoscope has the provision of setting a threshold voltage on the rising edge to trigger the recording. The output of the picoscope is connected to another PC(2) and the GPS was connected to the COM 1 port of $\mathrm{PC}(2)$. The sferic waveforms and their spectrograms were recorded during the first $5 \mathrm{~min}$ of every hour of the day.

\section{Results and discussion}

\subsection{Sferic field recording and analysis}

The software for the picoscope was loaded into PC(2). TAC 32 software was used to synchronize the computer clock of PC(2) with the GPS. When the picoscope was run without setting a threshold voltage, it recorded a background noise $\sim 0.35 \mathrm{~V}$, together with large changes in the voltage which were presumed to be due to the sferics. Hence, in recording the waveforms the threshold was set at $0.4 \mathrm{~V}$. Preliminary recordings of the waveform showed that the oscillatory pattern lasted $\sim 2 \mathrm{~ms}$. With a sampling rate of $333 \mathrm{~ns}$ (maximum for the picoscope) it was decided to acquire $8192\left(2^{13}\right)$ samples to record the waveform. Thus, when the input voltage crosses the threshold set on the software, the picoscope starts acquiring the data and continues for $\sim 2.75 \mathrm{~ms}$ and stores them in a file. The data recorded in $\mathrm{PC}(2)$ were then used to plot the waveforms using MATLAB. At this stage, the beginning of each waveform is known only up to a second of the GPS time. This is because even when PC(2) is initiated at a predetermined exact time, the picoscope starts acquiring data only when the incoming voltage crosses the threshold voltage. When the data is retrieved, the time of the beginning of the file is displayed up to s (PC time). However, this start time of the trace is not necessary for the procedure described in this paper. The times of the subsequent crossings of the waveform with the $t$ axis, which are necessary for the computation of $d$, are measured by the picoscope with a precision of $333 \mathrm{~ns}$. 


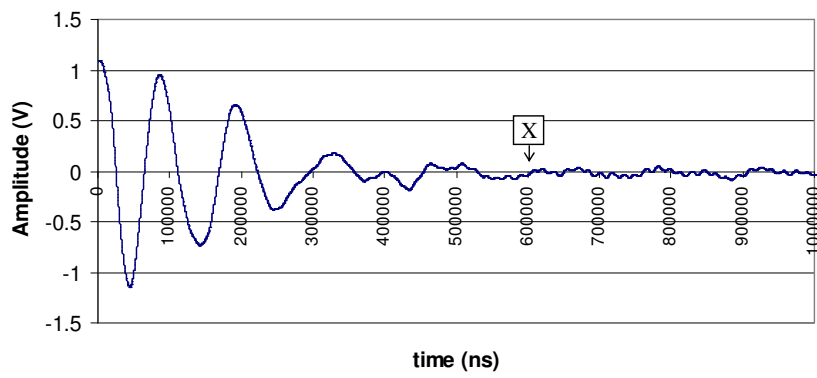

Fig. 3. Picoscope output of the sferic waveform (28 September 2006, 18:01:04 LT-06:01:04 UT).

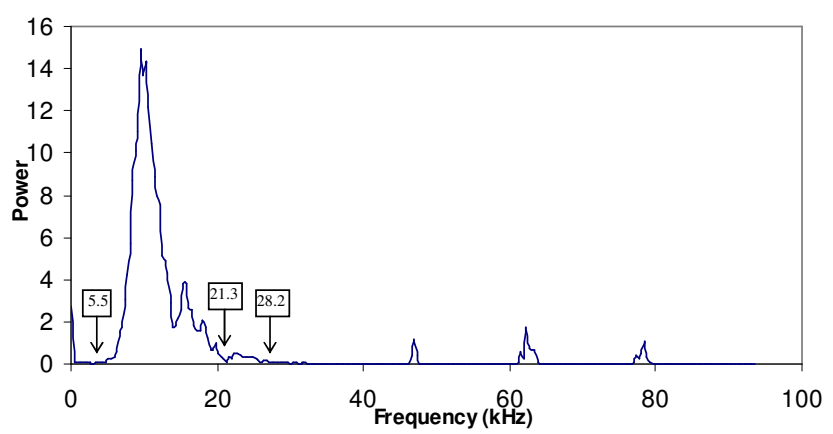

Fig. 4. The power spectrum of the sferic.

Figures $2 \mathrm{a}-\mathrm{d}$ show typical waveforms recorded at different times of the day and on different days. The times and days corresponding to the waveforms in Fig. 2 corresponded with WWLLN detection (detail discussion in Sect. 4.2). The traces show that, in the oscillatory region of the field, the wave pattern expands with time. In all the traces analyzed (77), the number of full waves varied from 4 to 8 , more than $70 \%$ of them having at least 6 full waves. The general quasi-periodical form (including noise) did not have any dependence on the sferics' arrival time or the distances they have travelled. For detail analysis presented in this section, a waveform was selected whose time corresponded to the detection by WWLLN, and also we were able to record the spectrogram of the sferics corresponding to the lightning. Figure 3 shows the waveform recorded on 28 September 2006, at 06:01:04 UT, which is 18:01:04 LT. The "noise"like pattern after $1.0 \mathrm{~ms}$ continued up to $\sim 2.75 \mathrm{~ms}$.

FFT analysis of the entire waveform shown in Fig. 3 was performed with MATLAB and the power spectrum, in arbitrary units, is shown in Fig. 4.

The VLF region of the sferic showed waves with peak powers $\sim 9.5 \mathrm{kHz}$ and $\sim 10.3 \mathrm{kHz}$, with two more groups of waves $\sim 15.8$ and $\sim 18 \mathrm{kHz}$, but with reduced power. The power spectrum starts at $\sim 5.5 \mathrm{kHz}$ and dies off after $28.2 \mathrm{kHz}$, with a dip in power at $21.3 \mathrm{kHz}$. Small peaks at higher frequencies $(\sim 46.9,62.3,78.5 \mathrm{kHz})$ were also observed. When the FFT analysis was repeated for the wave-

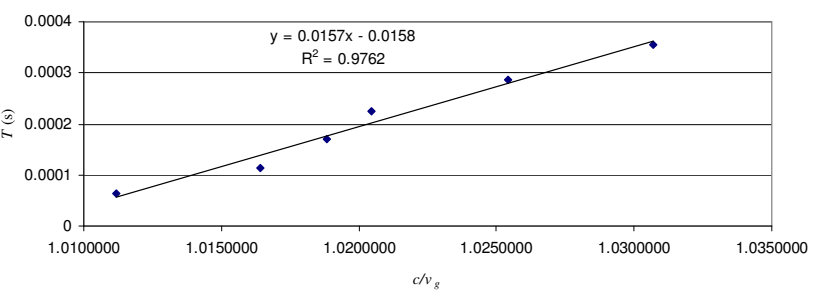

Fig. 5. Graph of quasi-wave period vs. $c / v_{g}$.

Table 1. Frequency and half-power band spread of the quasiperiodic waves.

\begin{tabular}{ll}
\hline$f$ calculated $(\mathrm{Hz})$ & Half-power band spread $(\mathrm{Hz})$ \\
\hline 11462 & $6232-13930$ \\
9503 & $4766-11000$ \\
8885 & $4766-11000$ \\
8531 & $4399-10260$ \\
7680 & $3299-8065$ \\
7016 & $2933-7332$ \\
\hline
\end{tabular}

form from the beginning to the point marked $\mathrm{X}$ in Fig. 3, the minor peaks appearing above $60 \mathrm{kHz}$ almost vanished and the peak at $46.9 \mathrm{kHz}$ reduced, confirming that the initial portion of the waveform carried the VLF signal.

For the waveform in Fig. 3, the frequencies of the quasiperiodic waves were calculated using Eq. (7). To calculate the frequency of the quasi-periodic wave, the time of crossing the $t$ axis was determined by the MATLAB program. FFT analysis was also done for each of the quasi-periodic waves, and their half-power bandwidths were calculated. The results are summarized in Table 1. The calculated frequencies of the quasi-periodic waves are within the half-power band spread of the FFT. This is to be expected since each of the quasiperiodic waves given in the trace are assumed to be due to the superposition of many waves whose frequencies are around the calculated frequency.

Considering more than 450 tweeks at our station during a two-year study (2003-2004), Kishore et al. (2005) showed that the nighttime cutoff frequency for the fundamental mode varied between $1.6-1.8 \mathrm{kHz}$. Figure 5 shows the plot of measured $T$ against $\left[1-\left(\frac{f_{c}}{f}\right)^{2}\right]^{-\frac{1}{2}}=\left(c / v_{g}\right)$, where $f$ is the frequency calculated from the wave pattern and $f_{c}$ was assumed to be the mean cutoff frequency $1.7 \mathrm{kHz}$.

It could be seen from the plot that the slope of the graph and the modulus of the intercept are nearly equal, with a variation of $< \pm 0.4 \%$ of the mean value. For the field pattern shown in Fig. 3, the estimates of the lightning strike's distance are $4981 \mathrm{~km}$ and $5021 \mathrm{~km}$, calculated from the slope and intercept of the graph, respectively. 
Table 2. Sample WWLLN data.

\begin{tabular}{llll}
\hline Date and Time UT & Latitude & Longitude & $\begin{array}{l}\text { No. of } \\
\text { stations }\end{array}$ \\
\hline 28 Sep 2006, 06:01:03.436155 & 7.1199 & 110.4846 & 5 \\
28 Sep 2006, 06:01:04.908366 & 24.3935 & 128.7729 & 7 \\
28 Sep 2006, 06:01:07.705695 & 36.353 & 22.5975 & 6 \\
\hline \multicolumn{5}{c}{ westward } \\
28 Sep 2006, 06:01:02.947788 & 18.7792 & 73.9523 & 6 \\
28 Sep 2006, 06:01:16.737547 & 7.2238 & 79.0363 & 8 \\
\hline
\end{tabular}

\subsection{WWLLN data and distance estimation}

The WWLL Network confirms that lightning has occurred when 5 or more stations have recorded the sferic (Rodger et al., 2006). WWLLN provides the participating stations with CDs, every month, which when read with MATLAB, give the date, the time of the lightning strike in UT, accurate up to a $\mu$ s with respect to GPS time, the coordinates of the stroke and the number of stations that recorded the sferic. As explained in Sect. 4.1, when the data of the waveform is retrieved from $\mathrm{PC}(2)$, the beginning of the file is displayed up to s (PC time). The computer clock of PC(2) was synchronized with the GPS clock. To identify the location of the lightning, on 28 September 2006, over the entire globe, MATLAB codes were written to analyze the WWLLN records for latitude $-90^{\circ}$ to $+90^{\circ}$, longitude $0^{\circ}$ to $+180^{\circ}$ (eastward) and $-180^{\circ}$ to $0^{\circ}$ (westward). The WWLLN records were then manually analyzed to identify any lightning detection around the time the waveform of Fig. 3 was recorded (06:01:04 UT). The time interval for the search was $\pm 1 \mathrm{~s}$ of the UT. The section of the data on 28 September 2006 around 0.6:01:04 UT is shown in Table 2. The last column in Table 2 refers to the number of stations that recorded the sferic impulse. We observe that a lightning strike has occurred at 06:01:04.908366 (UT). The WWLLN record does not show any other lightning around this time (accurate to s). This leads us to conclude that the field pattern recorded at our station may have been due to the lightning strike at 06:01:04.908366 (UT) at Lat. 24.3935, Long. 128.7729, as estimated by the WWLLN.

The great circle distance between the identified location and the measurement site was calculated using the website http://www.movable-type.co.uk/scripts/LatLong.html. This program uses the "Haversine" formula to calculate the distance. The calculated distance using the location was $5165 \mathrm{~km}$. The distances calculated using the approach we adopted in this paper was from the slope $4981 \mathrm{~km}$ and from the intercept $5021 \mathrm{~km}$. The average deviation in $d$ calculated from the slope and the intercept, compared to that calculated

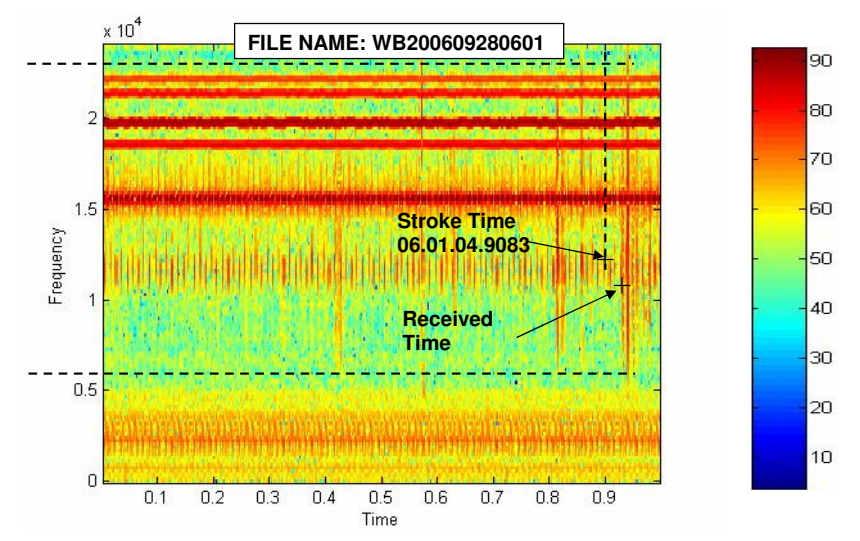

Fig. 6. Spectrogram display of sferics received in 1 s and the colour chart.

from WWLLN coordinates, is $\sim 3.2 \%$. For the stroke corresponding to the time 06:01:03.436155 the distance calculated using the coordinates was $7960 \mathrm{~km}$, hence this was disregarded.

\subsection{Spectrogram recording and analysis}

The WWLLN program for recording the TOGA was used to simultaneously record the VLF data, via a separate sound card, to give the spectrogram of the sferics. A program was written to start recording the VLF sferic data exactly at the hour and to record for $5 \mathrm{~min}$, and then to repeat the steps every hour. A one-minute record of the data will be stored in a file of $11 \mathrm{MB}$, thus five files will be created in the $5 \mathrm{~min}$. When one of these files is analyzed using MATLAB codes, it will show 60 spectrograms, each of $1 \mathrm{~s}$ in duration. If the sferic corresponding to the lightning that produced the field pattern of Fig. 3 has been recorded in the spectrogram, it should appear after the stroke time 06:01:04.908366 (UT), due to the travel time delay. The spectrogram which was recorded at 06:01:04 on 28 September 2006 was extracted from the files and is shown in Fig. 6. Note that 06:01:04 is the start time of the spectrogram. In the spectrogram, the stroke time is indicated by a vertical dashed line. It can be seen that 2 sferics appear after the stroke time.

In the spectrogram when the intensity of the sferic is large, the sferic appears reddish in color (refer color chart). The intensity of the spectrogram can be analyzed to give a qualitative interpretation of the spectrum of the sferics. The intensities of the 2 sferics were analyzed and compared with the FFT pattern in Fig. 4. This will enable us to identify the sferic that caused the field pattern of Fig. 3. For the sferic marked with a + sign, we estimate that appreciable intensity (above the noise level) starts from $\sim 5.8 \mathrm{kHz}$, goes to a maximum at $\sim 10.5 \mathrm{kHz}$, reduces and dips to a lower value at $\sim 20.6 \mathrm{kHz}$, increases and then decreases and dies off after $\sim 23 \mathrm{kHz}$ (below the noise level). The two extreme frequencies are denoted by the two horizontal dashed lines in the spectrogram. 


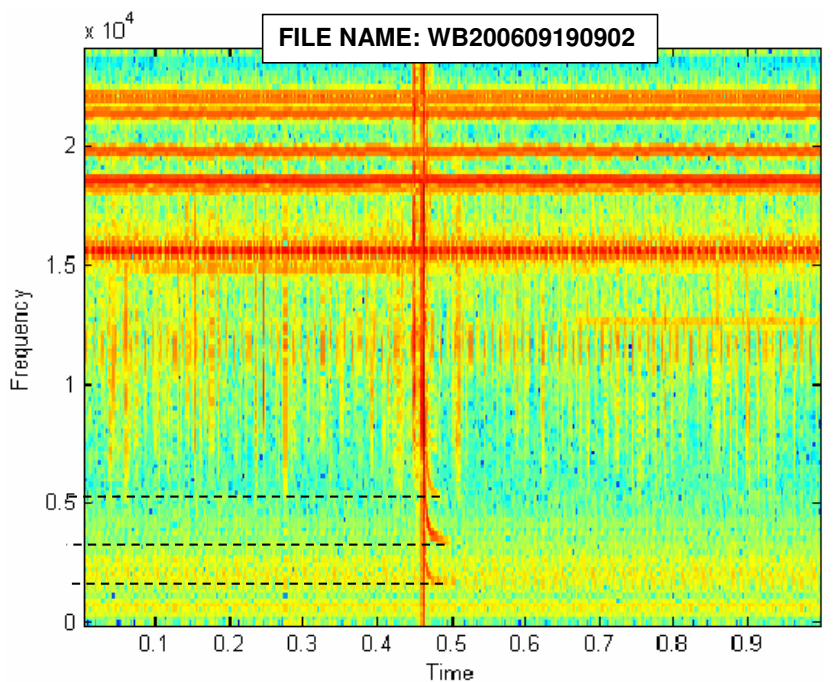

Fig. 7. Spectrogram showing tweeks.

The power spectrum in Fig. 4 shows that the limits of the VLF spectrum are $\sim 5.5$ and $\sim 28.2 \mathrm{kHz}$, with a dip in power appearing at $21.3 \mathrm{kHz}$ and an appreciable amount of energy lies between $\sim 6$ to $20 \mathrm{kHz}$. The very strong sferic adjacent to the one we have identified (+ sign) had appreciable energy below $5 \mathrm{kHz}$ and above $24 \mathrm{kHz}$ (which is the limit of the spectrogram). Therefore, we conclude that the sferic marked with + sign was the sferic corresponding to the field pattern recorded in Fig. 3. The time of arrival of the sferic (marked with + ) is 06:04:01.92533 UT. By taking the WWLLN stroke time and the arrival time of the sferic at our site, the distance it has traveled is $\sim 5090 \mathrm{~km}$, which is in good agreement with the distance calculated earlier $(5165 \mathrm{~km})$ with the WWLLN location. The deviation in $d$ calculated, compared to that calculated from WWLLN coordinates, is $\sim 1.5 \%$. The arrival time of the second sferic gives $d=9080 \mathrm{~km}$, which is very large compared to the $d$ calculated using the location coordinates. An explanatory note on the sferics: 1) even though there are many sferic lines on the spectrogram in this 1-s window, no lightning was recorded by WWLLN. As said earlier, WWLLN confirms a strike only when 5 or more stations record the sferic. 2) It has been reported (Jacobson et al., 2006) that the threshold current for detection by WWLLN is high thus the detection efficiency is low; hence, it may be that these sferics were not recorded at other stations. The lower frequency of the sferic, which is seen in the spectrogram, does not go up to the cutoff frequency of the EIWG. This is because the intensities of the fields have died off.

A tweek shown in Fig. 7 was recorded on 19 September 2006 at 09:02:39 (UT). From the spectrogram, we estimate that the cutoff frequencies of the fundamental mode as $\sim 1.7 \mathrm{kHz}$, which is the $f_{c}$ used in our calculations. The cutoff frequencies of the higher modes are $\sim 3.4 \mathrm{kHz}$ and $\sim 5.2 \mathrm{kHz}$, respectively. The waveform was poor to estimate

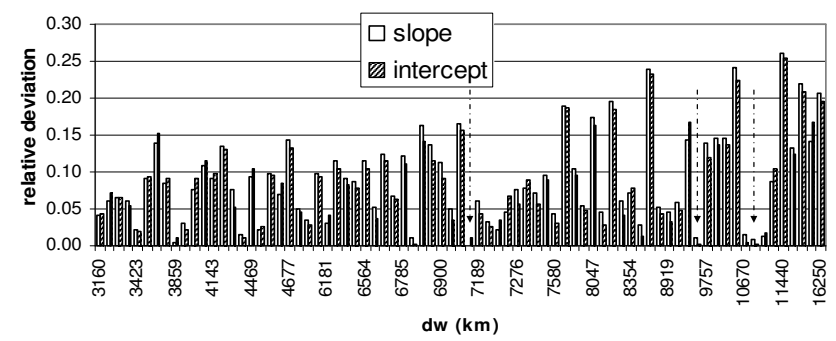

Fig. 8. Variation of deviation with distance $d_{w}$.

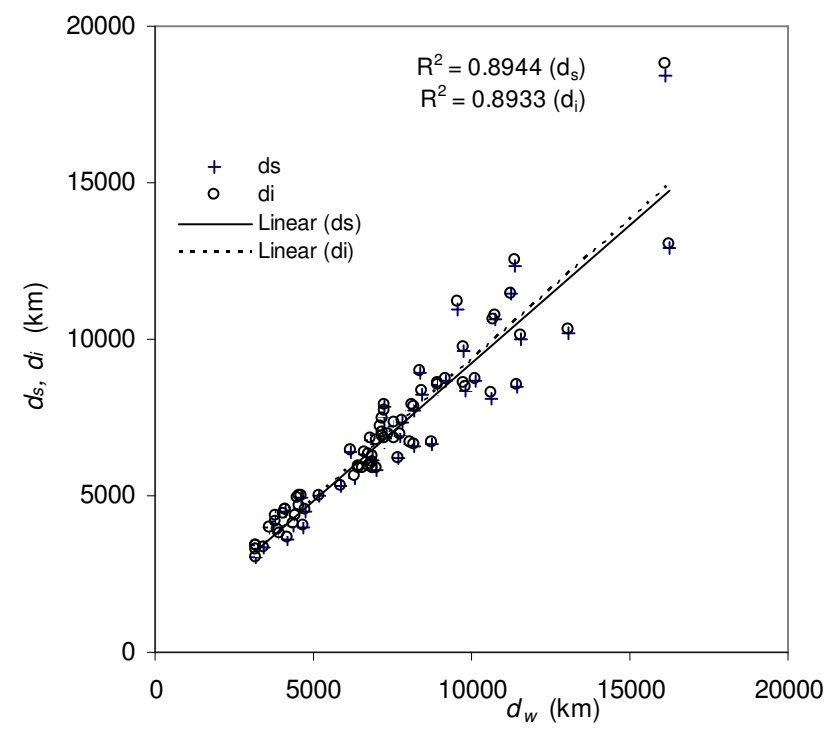

Fig. 9. Correlation of distances $d_{s}$ and $d_{i}$ with $d_{w}$.

the distance from it. Further, the time of capture of this sferic did not correspond to the WWLLN time of detection of lightning. The FFT of the field pattern did not show a cutoff frequency, as the spectrogram was extending to zero frequency.

\subsection{Comparison of distances estimated by the proposed method and WWLLN data}

One month (1-30 September 2006) of the WWLLN data and the 5-min hourly waveform patterns recorded during this period were analyzed. It was found that 108 corresponding events were present which were distributed between day and night. The daytime cutoff frequency is not well known for this region, thus our analysis is restricted to the nighttime records. For the waveforms shown in Figs. $2 b, c, d$ and Fig. 3 the estimated distances from the slopes of the graphs $\left(d_{s}\right)$ from the intercept $\left(d_{i}\right)$ and those calculated using the WWLLN locations $\left(d_{w}\right)$ are summarized in Table 3 . In the table $\Delta_{s}$ and $\Delta_{i}$ are the relative deviations (in \%) in estimating $d_{s}$ and $d_{i}$, compared to $d_{w}$.

Of the 77 coinciding nighttime incidences, which were recorded in one month, the distances calculated varied in 
Table 3. Comparison of estimated distances of lightning strikes.

\begin{tabular}{llllllll}
\hline Date and Time $(\mathrm{UT})$ & Latitude & Longitude & $d_{s}(\mathrm{~km})$ & $\Delta_{s}$ & $d_{i}(\mathrm{~km})$ & $\Delta_{i}$ & $d_{w}(\mathrm{~km})$ \\
\hline 8 Sep 2006, 07:00:28.896655 & 2.4901 & 112.359 & 7246 & $4.4 \%$ & 7356 & $2.9 \%$ & 7580 \\
3 Sep 2006, 11:00:06.481245 & 19.2788 & -101.021 & 9116 & $6.3 \%$ & 9230 & $5.1 \%$ & 9725 \\
24 Sep 2006, 03:04:04.208788 & 10.5992 & 102.4958 & 8514 & $4.5 \%$ & 8620 & $3.4 \%$ & 8919 \\
28 Sep 2006, 06:01:04.908366 & 24.3935 & 128.7729 & 4981 & $3.6 \%$ & 5021 & $2.8 \%$ & 5165 \\
\hline
\end{tabular}

the range of $3160-16250 \mathrm{~km}$. The deviations in the distances $d_{s}$ and $d_{i}$ (i.e. $d_{w}-d_{s}$ and $d_{w}-d_{i}$ ) were both positive and negative compared to the estimate from WWLLN data. Figure 8 shows the magnitude of the deviation (i.e. $\left|d_{w}-d_{s}\right| / d_{w}$ and $\left.\left|d_{w}-d_{i}\right| / d_{w}\right)$ in estimating the distance of the lightning stroke using the slope and the intercept of the graph compared to $d_{w}$. It was noted that for 74 of the correlated strokes, the signs of $d_{w}-d_{s}$ and $d_{w}-d_{i}$ were the same. For the other three strokes, $d_{w}-d_{s}$ were positive while $d_{w}-d_{i}$ were negative. These three strokes are identified by the arrow marks in Fig. 8. Interestingly, the relative deviations in the estimated distances are small for these strokes. The averages of $\left|\Delta_{s}\right|$ and $\left|\Delta_{i}\right|$ were $9 \%$ and $8.5 \%$, respectively. Considering the procedures, using both the intercept and the gradient of the graphs, the average percentage deviation in estimating the distance is $\sim 8.8 \%$ with respect to $d$ calculated using WWLLN location data.

To understand the correlation between the distances calculated using the proposed single station technique and the multi-station technique, $d_{s}$ and $d_{i}$ were plotted against $d_{w}$ and are shown in Fig. 9. The linear correlation coefficients $\mathrm{R}$ for both graphs were 0.95 , indicating a strong correlation between the single station and multi-station methods. It is clear from the trend lines that when $d$ is large, the correlation in the distance calculated using the method proposed and that calculated from coordinates predicted by WWLLN decreases.

\section{Conclusion}

The simple technique described in this paper provides two independent methods of estimating the distance of lightning from the sferics' waveform at a single station. The spectral analysis of one of the waveforms shows that the frequencies below $\sim 5.8 \mathrm{kHz}$ die off and does not show the cutoff frequency of the EIWG. This is confirmed by the intensity of the corresponding spectrogram. By matching the intensity of the sferics in the spectrogram with the FFT of the field pattern, the sferic which produced the waveform was identified. For this identified sferic the distance estimated from the travel time is within $1.5 \%$ of the distance calculated from the WWLLN location data. Compared to the distances calculated from the WWLLN locations, the deviations in $d$ calcu- lated from the intercepts were slightly lower than those calculated from the slopes of the graphs. The distances estimated ranged from $3160 \mathrm{~km}$ to $16250 \mathrm{~km}$. For $d$ in the range 3000 $3500 \mathrm{~km}$ the average deviation was $\sim 4.7 \%$ which is lower than those reported using other VLF single station lightning location techniques. For all 77 nighttime strokes considered in this study, the average deviation was $\sim 8.8 \%$, which is lower than many of the other reported VLF techniques. The deviations in the estimated $d$ increased as the distance of the stroke increase. When the distance is large, signals pass through the day/night terminator, hence the propagation conditions will change. We have assumed the nighttime cutoff frequency for the entire path, which will not hold true when waves pass through a mixed condition, when $d$ is large. By incorporating a direction finding arrangement, using the magnetic field components of the sferic, the system could be improved as a lightning location system.

Acknowledgements. The Authors wish to acknowledge the support of this research by the University Research Council through the grant 6C117-00.

Topical Editor F. D'Andrea thanks V. Mushtak and another anonymous referee for their help in evaluating this paper.

\section{References}

Boccippio, D. J., Wong, C., Williams, E. R., Boldi, R., Christian, H. J., and Goodman, S. J.: Global validation of single-station Schumann resonance lightning location, J. Atmos. Sol.-Terr. Phys., 60, 701-712, 1998.

Boccippio, D. J., Koshak, W. J., Christian, H. J., and Goodman, S. J.: Land-ocean differences in LIS and OTD tropical lightning observations, Proc. 11th Int. Conf. on Atmospheric Electricity, Huntsville, AL, National Aeronautics and Space Administration, 734-737, 1999.

Chronis, T. G. and Anagnostou, E. N.: Error analysis for a long-range lightning monitoring network of ground-based receivers in Europe, J. Geophys. Res., 108(D24), 4779, doi:10.1029/2003JD003776, 2003.

Cummins, K. L., Murphy, M. J., Bardo, E. A., Hiscox, W. L., Pyle, R., and Pifer, A. E.: Combined TOA/MDF technology upgrade of U.S. National Lightning Detection Network, J. Geophys. Res., 10, 9035-9044, 1998.

Dowden, R. L. and Rodger, C. J.: True global mapping of lightning using widely spaced VLF receivers on the ground, 27th General Assembly of URSI, Russia, 2001. 
Dowden, R. L., Brundell, J. B., and Rodger, C. J.: VLF lightning location by time of group arrival (TOGA) at multiple sites, J. Atmos. Sol.-Terr. Phys., 64(7), 817-830, 2002.

Hepburn, F.: Analysis of smooth type atmospheric waveforms, J. Atmos. Terr. Phys., 19, 37-53, 1960.

Itano, W., Nagano, I., Yagitani, S., and Ozaki, M.: Lightning location with single-station observation of VLF sferics, WAVE11P22, 2nd Kanazawa Workshop, Japan, 2006.

Jacobson, A. R., Holzworth, R., Harlin, J., Dowden, R., and Lay, E.: Performance Assessment of the World Wide Lightning Location Network (WWLLN),Using the Los Alamos Sferic Array (LASA) as Ground Truth, J. Atmos. Ocean. Technol., 23, 10821092, 2006.

Kishore, A., Kumar, S., and Ramachandran, V.: Observations of ELF-VLF sferics in the south pacific region, URSI 2005 New Delhi, 2005.

Lay, E. H.., Rodger, C. J., Holzworth, R. H., and Dowden, R. L.: Introduction to the World Wide Lightning Location Network (WWLLN), Geophys. Res. Abstr., 7, 02875, 2005.

Lee, A. C. L.: An experimental study of the remote location of lightning flashes using a VLF arrival time difference technique, Q. J. Roy. Meteor. Soc., 112, 203-229, 1986a.

Lee, A. C. L.: An operational system for the remote location of lightning flashes using a VLF arrival time difference technique, J. Atmos. Ocean. Technol., 3, 630-642, 1986b.

Lee, A. C. L.: Part B. Ground truth confirmation and theoretical limits of an experimental VLF arrival time difference lightning flash locating system, Q. J. Roy. Meteor. Soc., Part B., 115(489), 1147-1166, 1989.

Price, C., Asfur, M., Lyons, W., and Nelson, T.: An improved ELF/VLF method for globally geolocating spriteproducing lightning, Geophys. Res. Lett., 29(3) 1031, doi:10.1029/2001GL013519, 2002.

Ramachandran, V., Kumar, S., and Kishore, A.: Remote sensing of Cloud-to-Ground lightning location using the TOGA of sferics, Atmos. Sci. Lett., 6, 128-132, 2005.

Rafalsky, V. A., Nickolaenko, A. P., Shvets, A. P., and Hayakawa, M.: Location of lightning discharges from a single station, J. Gephys. Res., 100(D10), 20 829-20 838, 1995.
Rao, M.: Some experimental results of the study of VLFpropagation by means of sferics, J. Atmos. Terr. Phys., 30, 16671676, 1968.

Rao, N. N.: Elements of Engineering Electromagnetics, Prentice Hall, New Jersy, 2004.

Rison, W., Thomas, R. J., Krehbiel, P. R., Hamlin, T., and Harlin, J.: A GPS-based three-dimensional lightning mapping system: Initial observations in central New Mexico, Geophys. Res. Lett., 26, 3573-3576, 1999.

Rodger, C. J., Brundell, J. B., and Dowden, R. L.: Location accuracy of VLF World-Wide Lightning Location (WWLL) network: Post-algorithm upgrade, Ann. Geophys., 23, 277-290, 2005, http://www.ann-geophys.net/23/277/2005/.

Rodger, C. J., Werner, S., Brundell, J. B., Lay, E. H., Thomson, N. R., Holzworth, R. H., and Dowden, R. L.: Detection efficiency of the VLF World-Wide Lightning Location Network (WWLLN): Initial case stdy, Ann. Geophys., 24, 3197-3214, 2006, http://www.ann-geophys.net/24/3197/2006/.

Sao, K. and Jindoh, H.: Real time location of atmospherics by single station techniques and preliminary results, J. Atmos. Terr. Phys., 36, 261-266, 1974.

Smith, D. A., Eack, K. B., Harlin, J., Heavner, M. J., Jacobson, A. R., Massey, R. S., Shao, X. M., and Wiens, K. C.: The Los Alamos sferic array: A research tool for lightning investigations, J. Geophys. Res., 107(D13), 4183, doi:10.1029/2001JD000502, 2002.

Thomas, R. J., Krehbiel, P. R., Rison, W., Hamlin, T., Boccippio, D. J., Goodman, S. J., and Christian, H. J.: Comparison of ground-based 3-dimensional lightning mapping observations with satellite-based LIS observations in Oklahoma, Geophys. Res. Lett., 27, 1703-1706, 2000.

Uman, M. A.: The Lightning Discharge, Dover, New York, 1987.

Wait, J. R.: Electromagnetic waves in stratified media, Pergamon, New York, 1962

Wood, T. G. and Inan, U. S.: Long-range tracking of thunderstorms using sferic measurements, J. Geophys. Res., 107(D21), 4553, doi:10.1029/2001JD002008, 2002. 